\title{
RENAL LEIOMYOSARCOMA TREATED WITH PARTIAL NEPHRECTOMY
}

\author{
Marcello Cocuzza, Sami Arap, Antonio Marmo Lucon, and Luiz Balthazar \\ Saldanha
}

Primary sarcomas constitute from $0.8 \%$ to $2.7 \%$ of renal tumors in adults. ${ }^{1,2}$ Excluding Wilms tumors, $47 \%$ to $60 \%$ are leiomyosarcomas, 15\% liposarcomas, $9 \%$ hemangiopericytomas, $7 \%$ fibrosarcomas, $6 \%$ malignant fibrous histiocytomas, and 5\% rhabdomyosarcomas. ${ }^{1,2}$ The etiology of renal leiomyosarcoma remains obscure.

Radical nephrectomy was the treatment of choice used in all but 2 of the cases described, ${ }^{1,2}$ in which partial nephrectomy presented good results. ${ }^{3}$

\section{CASE REPORT}

A 52-year-old woman of mixed white and negro blood, suffering from diabetes mellitus, arterial hypertension, and stable angina, was undergoing treatment with enalapril, atenolol, hydrochlorothiazide, metformin, and aspirin. There was no significant familial history of neoplastic diseases. The physical examination was unremarkable. The complete blood count, blood biochemical values, and urinalysis were normal. She underwent magnetic resonance for assessment of the renal vessels, which were normal, though, incidentally, a 2-cm solid lesion was found in the left kidney (Fig. 1). The rest of the abdominal cavity was normal.

A partial nephrectomy was undertaken by means of lumbotomy; the surgical specimen revealed a clearly defined solid nodule measuring $1.7 \mathrm{~cm}$, surrounded by normal renal tissue, which did not extend outside Gerota's fascia (Fig. 2).

The histopathological examination demonstrated a lowgrade renal leiomyosarcoma with surgical margins that were negative for neoplasia. The immunohistochemical profile

Division of Urology, Hospital das Clínicas, Faculty of Medicine, University of São Paulo - São Paulo/SP, Brazil.

E-mail: mcocuzza@uol.com.br showed neoplasia of mesenchymal origin with myofibroblastic muscular differentiation (Fig. 3).

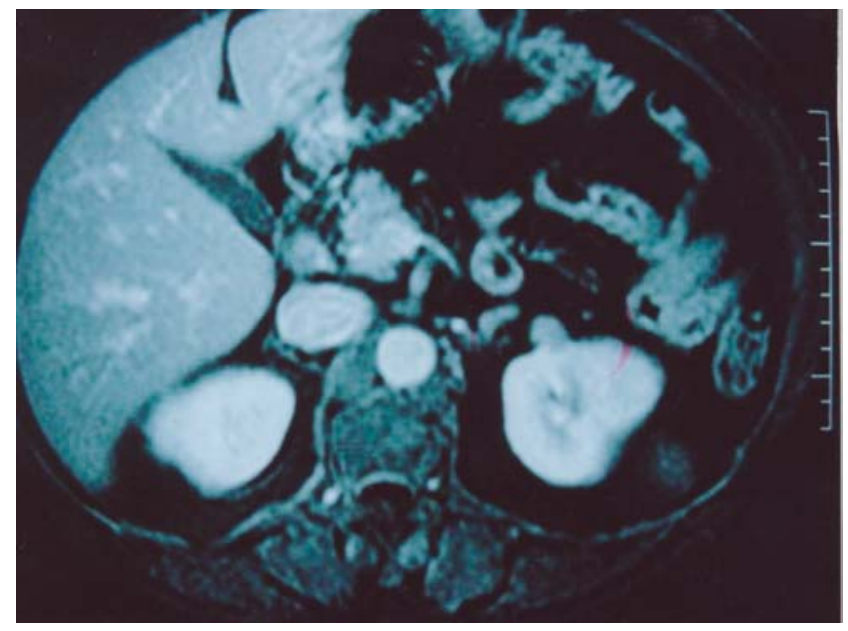

Figure 1 - Magnetic resonance angiography of the kidneys presenting a solid mass seen in the anterior aspect of the left kidney

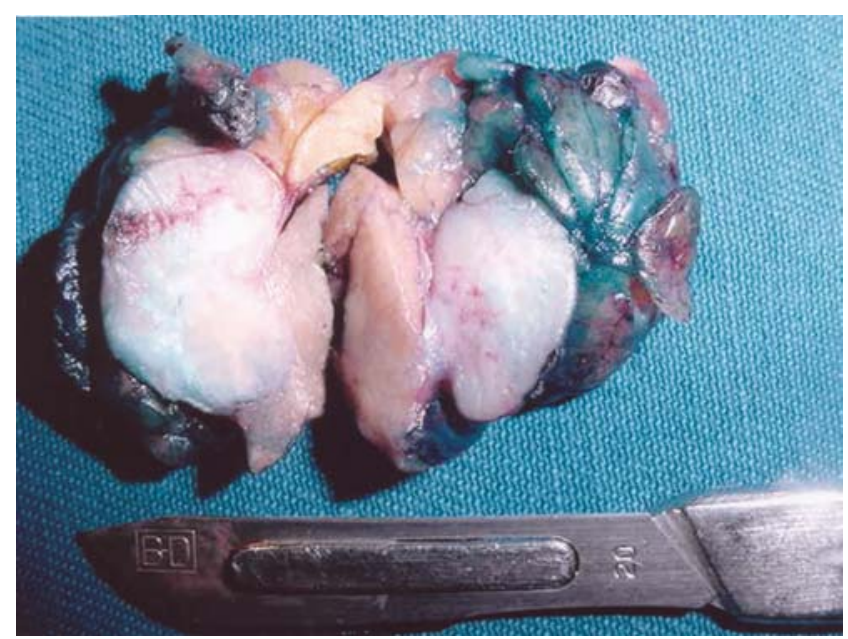

Figure 2 - Surgical specimen showing a $1.7-\mathrm{cm}$ solid nodule 


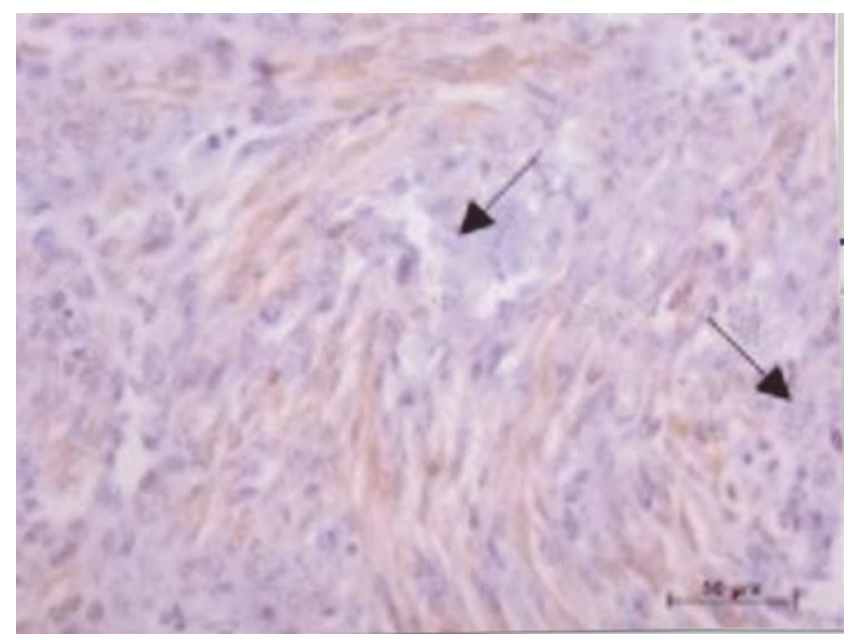

Figure 3 - Immunohistochemistry showing HHF expression in smooth muscle fiber cytoplasm. Nuclear hyperchromasia can be seen (arrows)

Neither adjuvant chemotherapy nor radiotherapy was applied to the patient. No evidence of local recurrence or distant metastasis was noted during 2 years of follow-up with computed tomography scanning.

\section{DISCUSSION}

Leiomyosarcoma of the kidney has a preponderance in women and is more frequent in the fourth decade of life but can be found at almost any age, with a gradually increasing incidence in the later period of life. ${ }^{4}$

Histogenesis remains obscure, because renal sarcomas may arise from the smooth muscles fibers of renal paren- chyma, renal capsule, renal pelvis, or renal vessels. ${ }^{2,5,6} \mathrm{Nei}-$ ther ultrasonography, tomography, or magnetic resonance are able to differentiate between leiomyosarcomas and renal cell carcinomas. They present as solid or cystic masses. The most common symptoms and signs are pain, palpable mass, and hematuria, all of which are indicators of an extensive local disease. ${ }^{2,3}$ Sarcomas of the kidney are very uncommon and are usually found as incidental tumors, as described in this case. This is also the tendency with other types of renal tumors due to the widespread utilization of transabdominal sonography and computerized tomography to screen for intra-abdominal and retroperitoneal diseases of any other organ. These incidentally-detected renal tumors tend to be smaller, earlier stage lesions that are amenable to organ-sparing surgery. ${ }^{7}$

Renal leiomyosarcomas have a very poor prognosis, with most patients dying within 2 years. ${ }^{8,9}$ It has been difficult to evaluate the true overall survival rate, as most reports do not have long follow-ups. ${ }^{4}$ Because of the poor outcome of renal sarcomas, adjuvant therapy is an attractive choice. Unfortunately, no role for postoperative chemotherapy or radiotherapy has been determined, ${ }^{8,10}$ although some reports suggest that adjunctive radiation and chemotherapy produce better survival rates than surgery alone. ${ }^{11}$

Although radical nephrectomy has been suggested as the treatment of choice, ${ }^{1,2}$ the excellent result obtained in this case and in 2 others through the use of partial nephrectomy, ${ }^{3}$ suggests that tumors of less than $5 \mathrm{~cm}$ should be treated by partial nephrectomy with all the resulting advantages described for this kind of treatment for renal cell tumors.

\section{REFERENCES}

1. Vogelzang NJ, Fremgen AM, Guinan PD, Chmiel JS, Sylvester JL, Sener SF. Primary renal sarcoma in adults. A natural history and management study by the American Cancer Society, Illinois Division. Cancer. 1993;71(3):804-10.

2. Kavantzas N, Pavlopoulos PM, Karaitianos I, Agapitos E. Renal leiomyosarcoma: report of three cases and review of the literature. Arch Ital Urol Androl. 1999;71(5):307-11.

3. Lacquaniti S, Destito A, Candidi MO, Petrone D, Weir JM, Servello $\mathrm{C}$, et al. Two atypical cases of renal leiomyosarcoma: clinical picture, diagnosis and therapy. Arch Ital Urol Androl. 1998;70(4):199201.

4. Niceta P, Lavengood RW, Jr., Fernandes M, Tozzo PJ. Leiomyosarcoma of kidney. Review of the literature. Urology. $1974 ; 3(3): 270-7$.

5. Gill IS, Hobart MG, Kaouk JH, Abramovich CM, Budd GT, Faiman C. Leiomyosarcoma of the main renal artery treated by laparoscopic radical nephrectomy. Urology. 2000;56(4):669.
6. Moudouni SM, En-Nia I, Rioux-Leclerq N, Guille F, Lobel B. Leiomyosarcoma of the renal pelvis. Scand J Urol Nephrol. $2001 ; 35(5): 425-7$

7. Aso Y, Homma Y. A survey on incidental renal cell carcinoma in Japan. J Urol. 1992;147(2):340-3.

8. Beccia DJ, Elkort RJ, Krane RJ. Adjuvant chemotherapy in renal leiomyosarcoma. Urology. 1979;13(6):652-4.

9. Srinivas V, Sogani PC, Hajdu SI, Whitmore WF, Jr. Sarcomas of the kidney. J Urol. 1984;132(1):13-6.

10. Kinsella TJ, Sindelar WF, Lack E, Glatstein E, Rosenberg SA. Preliminary results of a randomized study of adjuvant radiation therapy in resectable adult retroperitoneal soft tissue sarcomas. J Clin Oncol. 1988;6(1):18-25.

11. Davis R, Vaccaro JA, Hodges GF, Belville WD, Kiesling V, Jr. Renal leiomyosarcoma: plea for aggressive therapy. Urology. 1992;40(2):168-71. 